\title{
Divergencias, alternativas y transiciones de los modelos y las comunicaciones para el buen vivir
}

\author{
Divergent communication, Good Living and alternatives to \\ development \\ Comunicação divergente, Good Living e alternativas de \\ desenvolvimento \\ Arturo ESCOBAR, Colombia \\ Universidad de Carolina del Norte / aescobar@email.unc.edu \\ Manuel CHAPARRO, Chile \\ Universidad de Málaga / mch@uma.es
}

\footnotetext{
Chasqui. Revista Latinoamericana de Comunicación

N. ${ }^{\circ} 144$, Agosto-Noviembre 2020 (Sección Tribuna, pp. 19-36)

ISSN 1390-1079 / e-ISSN 1390-924X

Ecuador: CIESPAL

Recibido: 22-o9-2020 / Aprobado: 11-11-202O
} 


\section{Resumen}

Este artículo sintetiza el diálogo realizado entre el profesor PhD. Arturo Escobar y el Dr. Manuel Chaparro en torno a los ejes de sociedad, cultura y los desafíos de nuevos modelos divergentes para la comunicación. Aborda cuestiones clave sobre las críticas y transiciones hacia nuevos mundos y las propuestas y visiones alternativas para superar las nefastas consecuencias y crisis debido a la hegemonía del desarrollismo a nivel ambiental, social y de respeto a los derechos humanos y de la naturaleza tomando como eje las propuestas del buen vivir, especialmente inscritas en los debates del posdesarrollo.

Palabras clave: posdesarrollo, pluriverso, comunicación divergente, transiciones, buen vivir

\section{Abstract}

This article synthesizes the dialogue between Professor PhD. Arturo Escobar and Dr. Manuel Chaparro around the axes of society, culture and the challenges of new divergent models for communication. It addresses key questions about the criticisms and transitions to new worlds and the alternative proposals and visions to overcome the dire consequences and crises due to the hegemony of developmentalism at the environmental and social level and respect for human and natural rights, taking as its axis the proposals for good living and postdevelopment, especially inscribed in post-development debates.

Keywords: post-development, pluriverse, divergent communication, transitions, good living

\section{Resumo}

Este artigo sintetiza o diálogo entre o Professor Doutor. Arturo Escobar e Dr. Manuel Chaparro em torno dos eixos da sociedade, da cultura e os desafios dos novos modelos divergentes de comunicação. Aborda questões-chave sobre as críticas e transições para novos mundos e as propostas e visões alternativas para superar as terríveis consequências e crises decorrentes da hegemonia do desenvolvimentismo em nível ambiental e social e do respeito aos direitos humanos e da natureza, tomando como eixo o propostas de bem viver e pósdesenvolvimento, especialmente inscritas nos debates pós-desenvolvimento.

Palavras-chave: pós-desenvolvimento, pluriverso, comunicação divergente, transições, boa vida 
Manuel Chaparro1: Arturo, eres un referente dentro de la investigación, la divulgación y el activismo; de la denucia sobre los conflictos del desarrollo como práctica económica que nos está conduciendo a cotas desconocidas de inequidad y a un ecocidio que en muchos contextos parece irreversible. Esta situación nos lleva, entre otros, al debate sobre el papel de la comunicación, la información y las narrativas discursivas, pero también de los relatos que desde el común ponen el acento, más allá de la corrección político-académica y mediáticas, en representar las divergencias, la palabra en torno a la que gira esta conversación para examinar la centralidad de la comunicación desde diferentes miradas. La divergencia exige visibilizar las disidencias, las posiciones inconformes y las alternativas, desde una incidencia mediática que agite la reflexión sobre las transiciones y transformaciones necesarias. Tu usas dos ideas poderosas, como el Sentipensar y el Pluriverso. La primera rescatada por Fals Borda de los pescadores afrocolombianos caribeños. La segunda para hacer entender la complejidad de la diversidad frente a la homogeneización y los supremacismos culturales. Son cuestiones abordadas desde una formación multidisciplinar; ingeniero químico, filósofo, antropólogo y desde el compromiso social de quien está a caballo entre dos mundos llenos de contradicciones (Norte y Sur), que vienen a marcar de alguna manera las reflexiones contenidas en una tesis revolucionaria y atrevida, acerca de "La invención del Tercer Mundo"2. No solo pones el acento en los intereses coloniales, empresariales, corporativos y políticos que confluyen para generar una geoestrategia de la que surge un modelo económico, social e instrumental formativo, basado en la creencia de que solo el crecimiento económico, fundamentado en el consumo, puede hacer felices a las personas y propiciar bienestar, sino también en las graves consecuencias de esta doctrina economicista favorecedora de la inequidad, el empobrecimiento y la destrucción de ecosistemas. Hablaremos de todas estas cuestiones desde la comunicación y del rol que juega en este contexto, pero por situar las divergencias: ¿Podría decirse que Arturo Escobar es un antisistema que vive en el centro de un país (EE.UU) responsable de aplicar las recetas de la agenda del desarrollo al mundo? Un antisistema en el sentido de la manifiesta disconformidad con el sistema dominante.

Arturo Escobar: Gracias por la introducción y pregunta, a la vez que reitero un agradecimiento especial para CIESPAL y para ti. Yo creo que siempre he sido antisistema y la invitación que quisiera hacer es que todas y todos nos consideremos también antisistema. Esto lo digo porque vivimos en sistemas que nos están matando, que están matando el planeta y los seres humanos.

1 Este artículo sintetiza los debates principales que sus autores, Arturo Escobary Manuel Chaparro realizaron en el marco del "Diálogo Divergente", impulsado por el Centro Internacional de Estudios Superiores de Comunicación para América Latina- CIESPAL, con el apoyo de Fes comunicación y Fes ILDIS. Contó con la edición de Camilo Molina de CIESPAL.

Nota del editor: el texto al que se hace referencia es: Power and Visibility: The Invention and Management of Development in the Third World. Escobar, A. (1987) 
Quisiera comenzar con una proposición general que creo me permitirá sentar las bases para esta conversación: primero que todo, es una proposición doble o de una crisis doble. Por un lado, tenemos que aceptar que estamos en un momento de crisis planetaria (y en un momento mencionare algunas de las manifestaciones de esas crisis) y que, por tanto, si estamos en una crisis planetaria ${ }^{2}$, todas las formas de conocimiento, las tecnologías, las prácticas que han sido esenciales para la construcción de los mundos contemporáneos modernos y capitalistas, también están en crisis, lo que incluye a la comunicación y obviamente a la economía. El problema es que muy pocas dimensiones se declaran en crisis, por lo que mi invitación es a pensar que las comunicaciones se construyan a sí mismas como en crisis para que, de esta forma, miremos su transición hacia otros modelos comunicativos que estén al servicio de las transiciones civilizatorias a otros modelos de vida y de existencia que necesitamos urgentemente para sobrevivir. Esta es la segunda dimensión de la crisis.

Aquí es importante mencionar, muy brevemente, algunas de las manifestaciones de la crisis, que conocemos, porque donde quiera que miremos -si miramos hacia los ríos, hacia las montañas, hacia los océanos, hacia las ciudades, hacia los cuerpos mismos- vemos ejemplos de espacios, de ecosistemas, de entidades, de seres que están siendo vulnerados y destruidos. La misma pandemia de la COVID-19 ha sido abordada por personas expertas como una expresión que en última instancia se debe a la destrucción sistemática de los ecosistemas, al ir acorralando a todas las especies en espacios cada vez más pequeños y aunque el virus surgió en algún momento particular, en una ciudad y un mercado particular, detrás de todo esto lo que está es la destrucción sistemática de tantos ecosistemas en el planeta; si vemos el caso de los incendios forestales desde los casos de California, continuando con los incendios en Chile y en Australia del año pasado, la deforestación, etcétera, donde sea que revisemos encontraremos manifestaciones de la crisis. Creo que los únicos que no nos enteramos todavía somos los que tenemos el privilegio de vivir en clave de clase media o clase alta, pero la realidad es que el planeta entero con todos sus seres humanos y no humanos estamos en crisis.

Otro par de estadísticas que demuestran la profundidad de la crisis civilizatoria y que tú mencionas en uno de tus artículos recientemente, Manuel, es el hecho de que el diez por ciento de la población del mundo más rica controla el noventa por ciento de la riqueza global. Que el uno por ciento, el famoso uno por ciento, controla ya más de la mitad de la riqueza del mundo. Así, la distribución del ingreso de la riqueza expresa un mundo muy aberrante de desigualdad que subyace en la raíz de los modelos económicos que están destruyendo la tierra. Entonces recuperar la capacidad de respetar la tierra, de cuidar de la madre

2 Su denominación como crisis civilizatoria inició sobre todo con compañeras y compañeros indígenas desde el 1992 
tierra y el planeta que compartimos, también requiere disminuir y transformar esos modelos económicos tan desiguales.

Me ha impactado una estadística que leía en la revista Semana hace un año, que decía que en Colombia un millón de familias campesinas tienen menos tierra que una vaca. Esto es así porque en Colombia el uno por ciento de los terratenientes controla el 80 por ciento de la tierra, dentro de uno de los países más desiguales del mundo, combinado con la corrupción y la violencia, y buena parte de esa tierra está dedicada a la ganadería extensiva. Pero nos hemos acostumbrado a vivir en todo el mundo en países que, como Colombia, México, Brasil, y Estados Unidos incentivan la desigualdad. Dentro de este estado de cosas me parece que es una pregunta clave en esta apertura, pues lo que está en crisis es un modelo particular de vivir, un modelo de existencia -que denominamos capitalista, blanco y heteropatriarcal- con un incremento de la barbarie patriarcal con casos como los de Trump, los Bolsonaro, los Uribe y los Duque. Esto se observa en los nuevos presidentes de derecha, todos patriarcas violentos, dispuestos a aniquilar o hacer lo que sea para mantener su poder racista y xenófobo. Por eso hay movimientos tan importantes que les resisten como "las vidas negras importan" y los de reivindicación de los pueblos indígenas.

Son todas esas características del sistema las que tenemos que enfrentar y por eso tenemos que ser todas y todos antisistema o por lo menos buscar otros sistemas posibles, otras formas diferentes de las de los últimos setenta años de desarrollo. Termino aquí con otra idea: las últimas siete décadas de la era llamada desarrollo iniciadas desde la década de los cincuenta, han coincidido con un aumento impresionante de la desigualdad y la devastación ambiental, de tal modo que, si bien se puede argumentar que el "desarrollo" ha tenido muchos logros y progreso en cierto nivel material y para ciertos grupos sociales minoritarios, para la gran mayoría y para el planeta ha sido todo lo contrario. Los ecólogos se refieren también a este período como la fase de la gran aceleración, por la intensificación del uso de materias primas, energía y los recursos de la tierra -que se ha disparado de una forma impresionante- para mantener un estilo de vida cada vez más consumista. Todo esto equivale a un aumento de lo que el Movimiento de Mujeres Indígenas por el Buen Vivir, iniciado por valientes y lúcidas mujeres Mapuche- han llamado muy bien el terricidio: el asesinato sistemático de la madre tierra. Así, se expresa esta doble crisis, crisis civilizatoria por un lado y la crisis en el campo de la comunicación y el diseño por otro.

MCH: Hablando de la crisis en la comunicación, obervamos como pese a los cuestionamientos fundamentados en realidades incontestables y al crecimiento de una mayor conciencia social, los mensajes de los medios masivos son contradictorios, chocan y contradicen la realidad al no poner el acento en las causalidades y solo atender las casualidades informativas, negando realidades e invisibilizandolas. Por otra, se siguen defendiendo tesis y postulados genocidas 
como las centradas en la llamada Comunicación para el Desarrollo y el Cambio Social. Incluso se habla también de Educación para el Desarrollo y se vincula a un concepto freirano, cuando Freire jamás fue un desarrollista, la comunicación y la educación en Freire buscaban liberar, empoderar. Hace falta una crítica profunda para repensar estos términos por parte de quienes lo siguen usando, para ver cómo la comunicación puede insertar nuevos imaginarios que superen el desarrollo. Tú hablabas en algunas de tus intervenciones sobre cómo resistirse a la locomotora del capitalismo, la locomotora del desarrollo que viene avalada por el discurso mediático y el marquetín publicitario que le acompaña. Existe una necesidad obvia de romper con estas narrativas, pero ¿por dónde empezar a generarlas? ¿cómo recuperar el relato secuestrado por tanta propaganda medíatica?

AE: Se suele agregar cualquier cosa junto al concepto del desarrollo: comunicación para el desarrollo, educación para el desarrollo, participación para el desarrollo, desarrollo rural, salud para el desarrollo, desarrollo con perspectiva de género, etc. Con esto, lo que estamos haciendo es precisamente extender y expandir el espacio de aplicación de una forma de pensar, de un imaginario particular, que también es un mecanismo muy potente, es decir, el aparato del desarrollo: una serie de conocimientos y de prácticas que se han originado más que todo en los países ricos entre los años cincuenta y setenta, cuando los países llamados desarrollados partían del supuesto de que debían ayudar a desarrollar los llamados "países subdesarrollados" o del "tercer mundo". Como bien lo mencionaste, y como yo también lo indiqué en mi introducción, siete décadas de este proyecto de desarrollo no han arrojado resultados muy felices, no se han cumplido ni siquiera las metas que el mismo desarrollo se había planteado y por eso las seguimos reformulando. En el año 2000 se lanzaron los Objetivos del Milenio, que determinaron las políticas de desarrollo del año 2000 al 2015, pero en el 2015 las evaluaciones mostraron que no se habían cumplido casi ninguna de las metas a cabalidad; entonces se volvieron a lanzar otras metas, ahora del desarrollo sustentable a 2030, sobre las que va a pasar lo mismo. El desarrollo es como un juego que permite que los países más avanzados y las elites de los países del sur global -como llamamos ahora a países como los de América Latina y el Caribe- puedan continuar con su proyecto de construcción de un mundo basado en las reglas del capitalismo de mercado, de competitividad, productividad, eficiencia, etc. Pero, de nuevo, es ese sistema el que está en la base de la devastación ambiental, social y cultural que atravesamos.

Tomando esta crítica al desarrollo como punto de partida, quisiera que consideremos el siguiente postulado: que en vez de referirnos a comunicación para el desarrollo o de educación para el desarrollo, pensemos en cómo construimos la comunicación y la educación para ir más allá del desarrollo. A eso lo llamamos el posdesarrollo. Más aún, debemos pensar en comunicación para las transiciones civilizatorias para ir propiciando otros modelos de vida, de 
sociedad, donde realmente los humanos y la tierra puedan coexistir de una forma mutuamente enriquecedora, donde no privilegiemos solamente el proyecto de las cosas, del consumo, de la ganancia, la competitividad y la eficiencia. Ya debemos considerar seriamente que ese es el mundo que ya no deseamos y que tiene que quedar atrás si queremos salvar el planeta, y esto implica privilegiar una ética de construcción de un mundo donde quepan muchos mundos, en términos del cuidado del planeta y de la tierra, de nutrir relaciones mutuamente benéficas de los humanos entre sí y con la naturaleza. Luego revisaremos el rol de la academia en estos puntos.

MCH: Siguiendo tu argumentación es importante ser críticos con la reproducción, a veces inconsciente, del léxico que sostiene la tramoya utilitarista del desarrollo.Has citado algunas de las trampas que siguen estimulando la idea del desarrollo, que es camaleónica, se adapta a las circunstancias para sobrevivir. Usa camuflajes mediante calificativos a modo de pleonasmos que no alteran su significado, como advierte Latouche, local, humano, alternativo, verde... pero lo revisten simuladamente de una apariencia noble que permite construir una falsa ética para mantenerlo como principio hegemonico. Ahí está el invento del desarrollo "sostenible", otro eufemismo para defender más de lo mismo. Michael Braungart, químico aleman, que fue director de área de Green Peace, decía que el desarrollo sostenible no es más que un invento interesado, que resulta ser más de lo mismo y para reforzar la idea de nuestra dificil relación "sostenible" con el planeta contaba el chiste del que se encuentra con una persona amiga y le pregunta por cómo le va su relación de pareja y éste le responde: "sostenible". Una respuesta que da a entender que no hay una relación verdaderamente satisfactoria. La sostenibilidad no es mas que otro mantra a desmontar, aunque el esfuerzo sigue presentádose como titánico. Una de las principales dificultades, para cuestionar el desarrollo viene de esos disfraces favorecidos por los seudo consensos internacionales propiciados por agencias internacionales y financiados por las grandes corporaciones, construidos para propiciar el cambio de disfraz. Es como el refresco que cambia el mensaje con que publicita el producto sin alterar el contenido, no deja ser agua teñida azucarada con burbujas. La marca es el valor donde reside su fuerza y para mucha gente la marca "desarrollo" sigue funcionando, entre otras razones porque para los empobrecidos del sistema representa, en su imaginario, la única tabla de salvación en consonancia con los modelos de éxito exhibidos en los medios. Cuando la gente se ve obligada a pensar con el estómago, una realidad incotestable para una gran parte de la humanidad desheredada, es inevitable que se diga: tú cuestionas lo que ya tienes (el desarrollo), "cómo me dices que yo no puedo ser como tú." Es un argumento de peso, pero involuntariamente demagógico, porque no tiene en cuenta que la mejora de condiciones de vida de quienes han sido precisamente excluidos por el desarrollo, solo se revierte 
mediante la redistribución de la riqueza y adelgazando la parte obesa que acapara recursos sin necesidad.

AE: Hay muchísimas cosas allí en este comentario. Comencemos con el concepto de desarrollo sostenible o sustentable. Desde el comienzo, cuando se lanzó en 1987 la famosa comisión de Brundtland ${ }^{3}$ de las Naciones Unidas, se dieron críticas de que el desarrollo sostenible era un concepto insustentable porque era una contradicción en sus propios términos. No se pueden armonizar los intereses del desarrollo con los intereses del medio ambiente y de la tierra, por lo menos dentro de los marcos sociales y económicos conocidos de los modelos dominantes. El concepto de desarrollo sustentable seguía predicando que el crecimiento económico es necesario precisamente para reducir la pobreza y para proteger el ambiente. Sabemos que eso no ha ocurrido y que el crecimiento económico se ha disparado sin reducción de la pobreza- excepto en algunos casos- o de la desigualdad o del impacto sobre el medio ambiente. ¿Por qué ha sido así? A veces pienso que la economía, en su versión clásica y neoclásica, solo pueden ser economías del crecimiento, que no sabe decrecer, y hoy en día son muy importantes las propuestas del decrecimiento. Esto porque nos ayudan a pensar que la única meta de una sociedad no es seguir teniendo economías que crezcan, ya que lo hacen a expensas de los derechos de los pueblos y de la tierra.

Desde ese punto de vista, me parece que allí hay una ecuación perversa que tenemos que combatir. Tenemos que ser muy inteligentes para invertirla, pues, por un lado, dice que: para reducir la pobreza debemos tener desarrollo, para tener desarrollo debemos tener crecimiento económico, para el crecimiento económico es necesaria la extracción de los "recursos naturales"; y que si la naturaleza y la tierra sufren deben soportar este costo, o que podemos destruirlas o sacrificarlas. El crecimiento se convierte en una de las locomotoras del desarrollo, en lo que la administración de Juan Manuel Santos en Colombia denominaba precisamente como la locomotora minero-energética. En algún momento recuerdo que el gobierno de Santos declaró 17 millones de hectáreas en áreas del Amazonas y la zona de los Llanos Orientales de Colombia como lugares de "minería sustentable". Pero lo que está ocurriendo en realidad es la devastación del Amazonas y de los Llanos donde empieza ese tipo de minería, y esta ecuación es algo que todos los gobiernos de América Latina han usado, incluyendo a los progresistas.

De este modo, hay que combatir esa ecuación, y tenemos que buscar una que se base en la convicción de que lo que es bueno para la tierra es bueno para la gente, como nos lo dicen muy bien muchos pueblos originarios. El mismo concepto de terricidio que mencionaba sugiere que cuando se destruye la tierra se destruyen las condiciones de vida para que los campesinos, los afros descendientes, los pueblos indígenas, puedan vivir tener su buen vivir. Por

3 Nota del editor: el Informe Nuestro Futuro Común (1987) se conoce más como Informe Brundtland en referencia a la responsable de su publicación, Gro Harlem Brundtland, presidente de la Comisión Mundial de Medio Ambiente y Desarrollo de Naciones Unidas. 
tanto, para que toda la humanidad tenga un buen vivir también tenemos que empezar a reivindicar la posibilidad de que pueda haber una armonización real entre los intereses de la tierra y los intereses de los pueblos y los colectivos en todo el mundo. Hasta podemos decir que esto sirve para los mismos ricos. Porque, en última instancia, los súper-súper ricos siempre estarán protegidos a todo nivel, pero para la mayoría de gente del mundo, incluyendo las clases medias, la vida se va a poner cada vez más difícil, y este movimiento no va a parar, ni a nivel social o ecológico. Seguirán llegando pandemias, rebeliones y grandes levantamientos porque el estado de cosas en el que se encuentra la mayoría de la gente simplemente no se puede tolerar. Así, pensemos que lo que se debe sostener no es este modelo económico, que en realidad es anti-vida. Lo que se debe sostener con las condiciones para el florecimiento de la vida. Por esto tenemos que diseñar algo diferente que incluya formas de pensar diversas y otras formas de existir.

MCH: Señalas algunos ejemplos de la inequidad provocada por el desarrollo que son coincidentes en otros contextos en países definidos como primer mundo. En España, con 45 millones de habitantes existen 13 millones de personas empobrecidas: En el contexto de la UE, más de 100 millones, el 22 por ciento de la población, esto demuestra que el desarrollo ni siquiera ofrece soluciones en aquellos países que lo promueven, porque no está en su ADN la redistribución de la riqueza. La inequidad crece de manera dramática cada año. En estas circunstancias, el confinamiento provocado por la pandemia de la COVID, también ha hecho tomar conciencia a parte de la población de la necesidad de modificar hábitos de consumo y de relaciones. Realmente podemos reducir el consumo a las cosas esenciales, a lo verdaderamente imprescindible sin que esto afecte a la calidad de vida. Porque el sobreconsumo de unos detrae recursos de muchos y destruye los ecosistemas. Logícamente, la transformación es compleja porque la falta de consumo en las cuotas exigidas por el desarrollo, también ha empobrecido la precaria economía de otras personas. El consumismo genera dependencias que impide el gobierno desde la soberanía personal y colectiva. Lo que nos indica que tenemos que buscar otras salidas y es a partir de ahí donde se construyen y diseñan nuevos escenarios para el posdesarrollo, el transdesarrollo, el postcapitalismo, el decrecimiento y, destacaría, el buen vivir. Este último concepto es importante porque estamos buscando alternativas y la salida ya está escrita en ese concepto que es universal, común a todas las culturas originarias precapitalistas. No se trata solamente de un concepto andino-amazónico como se ha estado diciendo, se encuentra en las raíces de otros pueblos y culturas de todos los continentes como los recogidos, entre otros, en el libro Pluriverso. Diccionario del Posdesarrollo ${ }^{5}$, del que eres coeditor. Pero, la cuestión es, cómo mirar más estos modelos originarios de las culturas precapitalistas para reaprender, para repensar los modelos sociales y encontrar luces sobre cómo viabilizar políticas de rescate ontológico para 
plantear las utopías necesarias. Es decir, el desafío es armonizar estas ideas en nuestra contemporaneidad.

AE: Exacto, hay dos partes en este comentario. Primero, volver a la pregunta del sistema y antisistema y revisar qué está pasando con el gran sistema global capitalista. Porque como señalas, esto no es cuestión solamente del tercer mundo o el sur global, sino que implica al primer mundo. Todos estamos de distintas maneras metidos en este modelo capitalista global que ahora llamamos neoliberal, y el neoliberalismo significa también que las economías prósperas ya no son economías de bienestar, con excepción parcial de los países escandinavos y algunos países europeos, pero incluso allí existen las presiones neoliberales para desmontar estos beneficios y comenzar ese proceso de hiperacumulación de la riqueza en los estratos superiores. Por esto, se ha tenido que inventar la categoría de los súper-súper ricos, pues el o.1\% de la población global controla una impresionante cantidad de riqueza, con un modelo, que, dicho de forma muy sucinta, no es bueno para la vida humana ni para la vida de los no humanos.

Segundo, la pandemia ha sido una ruptura y recordaba este lema o slogan que surgió en Chile en el 2019 al calor de las protestas: "no volveremos a la normalidad porque la normalidad era el problema". Además, esa normalidad de los sistemas es la que los medios propagan y celebran, en buena medida porque reproducen las mismas categorías y la visión del mundo que detentan los poderosos, limitándose a reportar el estado de ese mundo donde la fuerza está en esa economía, los mercados, el entretenimiento y el "emprendedurismo". Por el contrario, los medios no expresan cómo van los mundos del buen vivir ni cómo están sobreviviendo las personas, aún en medio de la crisis. Pero la pandemia también nos ha recordado que no son ni los banqueros, ni los economistas, ni los grandes científicos, ni los grandes empresarios los que sostienen y cuidan de la vida. Más bien los protagonistas son las personas pobres, la gente del campo, las mujeres quienes en buena medida que son las grandes cuidadoras del planeta, las que cultivan los alimentos, las que cuidan las semillas, las que cuidan el agua. Esto me lleva a la segunda parte de la pregunta acerca del buen vivir y a recordar que tenemos muchas respuestas. El mundo no sufre por falta de propuestas o por falta de respuestas, aunque es importante pensar las razones del porqué casi no las vemos casi o las consideramos.

El buen vivir, como se indicaba, nació en los Andes suramericanos, y expresa una reinvención, una rearticulación, una forma de hablar nueva desde los pensamientos críticos de los pueblos indígenas, los conocimientos afrodescendientes y campesinos sobre cómo la vida puede ser muy diferente. Ellos conocen que la vida puede ser de una forma diferente, por lo que el buen vivir sugiere que el fin de la vida social y de la política pública no puede ser solamente material y orientado a producir más y más mercancías, a aumentar el consumo ad infinitum, como si lo demás no contara. No podemos seguir subordinando el 
buen vivir o el bienestar de la mayoría a la economía y la tecnología, sino que tenemos que invertir esta forma de pensar, es decir subordinar la economía y la tecnología y bla política pública a las necesidades del buen vivir.

El buen vivir es una cosmovisión holística eintegral de la vida. En ellibro sobre el Pluriverso un diccionario para el postdesarollo, en el que soy uno de los cinco editores, insistimos en que el buen vivir y muchas otras visiones e imaginarios que vienen de muchas latitudes y culturas ancestrales están reinventando nuevas formas de buen vivir y que no se trata de volver a pasado como algunas veces se dice. Esto nos demuestra que sí tenemos muchas visiones y propuestas alternativas viables sobre cómo puede ser ese tránsito, y que el buen vivir es una alternativa al desarrollo y no una nueva forma de ver el desarrollo. Esta distinción es crucial, pues el buen vivir no se basa en el crecimiento económico o en una opción de la vida en donde la economía es lo que cuenta por encima de lo social, de lo cultural, de lo ambiental. No se basa en una separación de lo humano y lo no humano, sino que incluye una integración nueva del humano con la naturaleza, que supera el individualismo craso que nos han metido por todos los poros los medios masivos capitalistas de las sociedades modernas. Más bien se trata de visiones del mundo y construcciones donde lo personal y lo comunal coexisten de una forma mutuamente enriquecedora. Entonces en el buen vivir, en los buenos vivires porque se expresan de diferentes formas para cada comunidad, cada grupo social, cada nación.

MCH: Cuando mencionas los modelos de los proyectos promovidos por la economía de la transición, indicabas que no se toman suficientemente en cuenta, y no se trata solamente de los modelos de los pueblos originarios, tan importantes en el reaprendizaje y en el repensar. En el contexto europeo hay muchísimas experiencias que hemos puesto en nuestros mapas de transiciones (www.comandalucia.org) para dar a conocer modelos y para que los medios los usen como fuentes de información y ayuden a dar una visibilidad que favorezca las réplicas de estas experiencias exitosas que generan empleo y una economía circular basada en la ética ecosistémica.Parece que compartimos estos tiempos distópicos, con espacios de heterotopías como decía tu maestro Foucault ${ }^{6}$, espacios que motivan a los diálogos divergentes movilizadores de lógicas y autonomías más endógenas, de impugnaciones místicas pero también reales, acontecen en el mismo espacio-tiempo. Hay multitud de experiencias que conducen a las nuevas utopías o a las ecotopías, usando el nombre de la novela de Ernest Callenbuch (Ecotopía, 1975). Y aquí surgen las preguntas inevitables ¿cómo alimentar la utopía, sin caer en la quimera de un absurdo irrealizable o en la promesa a la que nunca se va a llegar? Reivindicar la utopía como motivación, como necesidad para generar una ilusión real en la construcción de otros modelos. 
AE: Me voy a referir a dos aristas en particular de este comentario: la primera, sobre los motivos por los que no se cuentan esas otras formas alternativas transformadoras. Y la segunda, sobre las nuevas utopías.

Para comenzar con la primera, me acordaba de una de esas frases tan efectivas que formula de Boaventura de Sousa Santos. Él dice: "lo que no existe [las alternativas radicales], no es porque no existan, sino que son activamente producidas como no existentes o como alternativas no creíbles de lo que existe". Todas esas alternativas transformadoras de los campesinos, de los pueblos indígenas, de los barrios populares urbanos, de los cuidadores de semillas, de las ecoaldeas, de todas estas otras formas de pensar y de hacer, no es que no existan, sino que se invisibilizan o desvalúan activamente por los discursos y cosmovisiones dominantes. Revertir esta situación será posible solo cuando los medios masivos sean más alternativos y radicales y surjan desde esos colectivos. Porque los medios actuales cuando cubren eventualmente estas realidades, se refieren a lo que se está haciendo diferente de una forma que lo minoriza, lo minimiza. Presentan las alternativas como realistas, como propuestas por románticos e ilusos. Yo creo que tenemos que invertir la postura que está presente en los medios masivos de todos los canales de televisión principales en América Latina. Por ejemplo, en Colombia el canal Tele Pacífico, sus noticias principales son completamente pro sistema y por eso nunca muestran toda la actividad tan impresionante que hay alrededor y de la gente que está defendiendo los páramos, los humedales, las fuentes de agua, otras formas de producir alimentos y de consumir alimentos, etc. Más bien cuando lo hacen siempre se realizan con descalificaciones, como experiencias que no son lo suficientemente creíbles o relevantes. Entonces invertir esta postura significa expresar que los románticos y los no realistas son quienes siguen diciendo que más de lo mismo nos va a sacar de la crisis, porque ya está comprobado que más crecimiento económico, más políticas del Banco Mundial, más intervenciones del Fondo Monetario Internacional, más multinacionales, más consumo, más tecnologías 5G, implican seguir devastando la tierra y seguir creando desigualdad y pobreza, porque esa es la experiencia de al menos los últimos 200 años.

La segunda parte, sobre la utopía, refiere a la cartografía de las transiciones. Sobre todo, pensaba en el famoso Atlas de justicia ambiental que el grupo de economía ecológica de la Universidad Autónoma de Barcelona ha estado haciendo por 10 años ${ }^{4}$; un mapa muy interactivo e interesante de los miles de conflictos ambientales importantes que hay en el mundo. Lo significativo de estas experiencias es que sea la misma gente que está resistiendo esos conflictos y que participa en las transiciones la que suba la información en la red, y se van estableciendo densas redes de alternativas, donde van surgiendo ideas impresionantemente viables. No solamente hermosas y contundentes,

4 Nota del editor: El mapa del Atlas de la Justicia Ambiental (EJAtlas - Environmental Justice Atlas), puede consultarse en: https://ejatlas.org/ 
sino viables acerca de cómo la alimentación puede ser diferente, la soberanía alimentaria, los sistemas agroecológicos, orgánicos. Sobre cómo podemos vivir en ciudades más amables, que no se construyan en contra de la naturaleza y cómo podemos pensar en la salud, en aprender en la educación y otras formas en cualquier área de la actividad humana. Esto evidencia que hay alternativas, pensamiento alternativo, formas creíbles y construibles de ser de otra forma y que están en esos espacios contestatarios, en esas heterotopías como las llamaba Michael Foucault. Pienso en tantas experiencias de jóvenes en las ciudades, en los barrios urbanos sobre todo populares, donde surgen estos espacios en los que la gente joven ya sabe que no quieren seguir viviendo de acuerdo al guion preestablecido que les ofrece como única alternativa ser "innovadores" y "emprendedores", lo cual es para la mayoría un espejismo.. Entonces, las utopías ya se están construyendo, las transiciones ya están ocurriendo y lo que tenemos que desarrollar es la capacidad de verlas y dejar de estar obsesionados con esas noticias que nos informan sobre el estado del mundo capitalista, racista patriarcal, así sea de vez en cuando mostrando las protestas y las resistencias, pero sobre todo evidenciando sus logros. Entonces, debemos desarrollar nuevos medios como parte de una praxis comunicativa para esas otras realidades que están surgiendo.

MCH: Importante esta reflexión sobre los relatos y la necesidad de esta nueva narrativa. Hay dos ejemplos conocidos de investigación y enseñanza que tratan precisamente de generarla: la Universidad de La Tierra en Oaxaca y la Universidad campesina del Mocase ${ }^{5}$. Son universidades que piensan el territorio, para intervenir en él y que trabajan por tanto un nivel de economía no especulativa, sino de economía local para favorecer los procesos desde la agricultura, la medicina, la veterinaria, la botánica, la biología, desde la música y la cultura propia. En el debate sobre la academia, tenemos que cambiar también la universidad y darle una autoridad que vaya más allá de estar discutiendo todo el día con los libros de biblioteca y vaya a la calle con la gente.

AE: Esta pregunta sobre la academia es difícil. Yo a veces digo algo que puede parecer demasiado radical, que la academia tomada como un todo -y enfatizo tomada como un todo porque siempre hay espacios de disenso dentro de cualquier institución incluyendo la académica-, es parte de las fuerzas de ocupación de la vida y de los territorios, de la gente, de los pueblos y de los colectivos. Lo digo porque la academia tiene la presión neoliberal y social de

5 Nota del editor: La Universidad de la Tierra es un espacio de reflexión de pensadores y movimientos sociales oaxaqueños, especialmente en temas agrícolas. Más información en: http://unitierraoax.org/ quienes-somos/nuestra-historia/.

La UNICAM SURI (Universidad Campesina - Sistemas Rurales Indocampesinos), es una universidad asociada al Movimiento Campesino Santiago del Estero (MOCASE) para la formación en la cultura y sistemas agrícolas propios, además de comprometerse con la educación de campesinos y personas de barrios marginales. Más información en: https://www.mocase.org.ar/secciones/universidad-campesina 
formar jóvenes que tengan éxito en economías globalizadas y es allí donde se forman los expertos, los ingenieros, los economistas, los administradores, abogados etc. que luego perpetúan esa misma visión del mundo que ya sabemos que es un callejón sin salida. Es decir, estamos entrenando cómplices con el terricidio, cómplices con los sistemas que crean tanta desigualdad y tanto sufrimiento en la vida social en todos los países del mundo.

La academia podría tener otro papel desde la tendencia latinoamericana de pensamiento crítico y el pensamiento decolonial, incluida la descolonización epistémica de la academia, aunque eso tiene varias fases. Una es liberar espacios dentro de las universidades y transformarla para acoger esos otros saberes, esas alternativas transformadoras de las que estábamos hablando. Eso está ocurriendo en muchos programas en universidades de todo el mundo. Siempre hay estos espacios interesantes donde activamente se incorporan otras alternativas como formas de conocimientos importantes para la vida y para la formación profesional. La otra expresión es crear universidades $u$ otras academias, como las Universidades de la Tierra en Oaxaca y Chiapas, o la Universidad de la Tierra en Manizales, Colombia que propone su influencia en un territorio grande que ahora se renombra como Kumanday, en el que confluyen pueblos y colectivos. Entonces estas universidades, indígenas, autónomas, de la resistencia, que no son universidades en el sentido formal pero que si entrenan personas en otras formas de conocer y aprender más vinculadas al buen vivir y enfocadas hacia cómo podemos abordar los problemas actuales más serios como el cambio climático, las desigualdades, etc.

Hay una cosa más que me gustaría decir sobre las comunicaciones como un espacio de pensamiento y de acción que concierne a las universidades. Es importantegenerar una mirada ontológica pluriversal sobre las comunicaciones. Es decir que las comunicaciones dejen de ser mayoritariamente una tecnología política para reportar y, por tanto, para reproducir el estado de cosas actual del pensamiento del sistema y sus realizaciones. De este modo, esa mirada ontológica debe aprender a cuestionar ese mundo único, supuestamente globalizado en términos de mercados, competitividad, eficiencia, al cual consideramos como la única forma posible de existir, pero que no lo es pues hay muchísimas formas de existir, un pluriverso de ellas. Así, volvemos al inicio mirando a la comunicación en crisis dentro de un mundo en crisis. Por tanto, construir una práctica comunicativa en transición al servicio de las transiciones requiere esa mirada ontológica que dé a las comunicaciones oportunidades para informar y producir imaginarios hacia otros mundos posibles -un mundo donde quepan muchos mundos como expresan los zapatistas con su gran sabiduría desde hace tiempo- en contra de ese mundo único globalizado. Pero también dicen las y los zapatistas que su proyecto no es para cambiar el mundo, porque ya ellos están convencidos de que este mundo no va a cambiar, desde adentro por lo menos, sino que se debe ir creando otros mundos. Por esto, las comunicaciones como praxis ontológica comunicativa para el buen vivir debe enfocarse en hacer 
visible, en poner en circulación y crear imaginarios para todos esos otros mundos posibles que van surgiendo y que en última instancia son la base que nos va a permitir convivir de nuevo, para reconstruir las formas de sociabilidad en términos de convivencia, convivialidad, cuidado, buen vivir, bienestar para todas y todos y para la madre tierra.

MCH: Una larga lista de tareas fundamentales que nos devuelve al eje de estos diálogos acerca de la importancia de una comunicación divergente. El problema con los medios, el problema con los imaginarios y cómo estos vienen a reforzar las propuestas denunciadas por Gustavo Esteva y Wolfgang Sachs, en el Diccionario del Desarrollo, un documento muy crítico $^{6}$, que seguramente ha conducido a una segunda parte en otra obra colectiva de calado, que mencionábamos antes: Pluriverso. Un diccionario del Posdesarrollo. El primero denuncia y el segundo pone el valor el espacio de transformaciones y toma de conciencia mundial sobre los caminos diversos del posdesarrollo. Un discurso propositivo desde las experiencias. Pero hay algo que me llama la atención, en ninguna de las dos obras se introduce la variable del rol de los medios de comunicación e información como factor determinante en la construcción de imaginarios y la movilización social. La transversalidad de la comunicación facilita la reapropiación de los relatos. Me parece importante en la tarea de transición el acompañamiento de nuevos modelos de medios que se constituyan en alternativas contrahegemónicas y den visibilidad a las nuevas propuestas de la sociedad civil, de manera que en contraste con los medios masivos convencionales, la ciudadanía ponga en valor esta información, una estrategia que también se debe acompañar con una labor de pedagogía con las audiencias y el sistema de medios en general.

AE: Exactamente, no asumir una audiencia monolítica que piense de una sola forma porque las audiencias son muy heterogéneas. Llamar a los medios masivos como un espacio de producción de conocimientos que deben tener también la la responsabilidad de producir otro tipo de conocimientos; este es un debate que casi no se da en los medios masivos. Por ejemplo, en Colombia con la decisión de la Corte Suprema de seguir un proceso y finalmente encarcelar a Álvaro Uribe V. por manipulación de testigos, la mayoría de los medios dieron simplemente la versión Uribista, y muy pocos de los mejores periodistas empezaron a cuestionar si los medios no deberían ir más allá y adoptar una postura crítica frente a esa hegemonía de discurso del poder. Entonces, tienes la razón en llamar la atención de esta ausencia explícita sobre las comunicaciones que debió haber estado allí, definitivamente. Son capítulos que quedarán por escribir.

6 Nota del editor: Se refiere a la obra de Sachs (1992). 
Pero sí quiero mencionar que en espacios como el Pacto Ecosocial del Sur ${ }^{7}$, una propuesta para transformar el horizonte de sentido en el que participa una serie de personas de América Latina y que recoge visiones y propuestas desde colectivos de movimientos y de academia critica, sí aparecen las comunicaciones como un espacio potencialmente contestario. Allí, se plantea recuperar el espacio de las comunicaciones de su control corporativo para empezar una labor comunicativa desde otros lugares muy diferentes de la sociedad civilunas comunicaciones realmente pluralistas. Como tú bien lo dices, tendrán que seguir reportando a los actores del poder pero abiertos cada vez más a otro tipo de narrativa y de imaginario.

MCH: Quedan algunas preguntas que nos trasladan al hilo de esta conversación. Voy a resumir brevemente algunas de estas inquietudes. Hay una preocupación en torno al desafío no solo de la apertura de medios, sino de que éstos lleven a cabo un cambio extremo, que aleje la idea de la buena vida y la felicidad vinculada a la práctica del consumo. Por otra parte, también preocupa que el concepto de buen vivir se utilice como estrategia de marquetín político, de la misma manera que los medios masivos resignificarlas alternativas de las culturas populares y las pervierten. ¿Qué se puede hacer para prevenir que el discurso político se apropie de las terminologías de la misma forma que el desarrollo construyó el imaginario del progreso y

la modernidad? ¿cómo evitar la apropiación del buen vivir para defender el capitalismo verde? Finalmente, ¿cómo limitar los abusos contra los derechos humanos y del Nuevo Orden, que se expresan en la brutalidad de la fuerza contra las marchas, por ejemplo en Colombia, y la represión contra los movimientos y sus expresiones para crear esos otros mundos? ¿Qué se puede hacer para prevenir estas prácticas?

De alguna manera creo que algunas de ellas han quedado respondidas. A mi especialmente me preocupa la urgente necesidad de democratizar el sistema de medios, de descorporativizarlo y desgubernamentalizarlo dando protagonismo al Tercer Sector para recuperar la fuerza del relato y crear narrativas propias.

AE: Definitivamente estos son ejemplo de la apropiación por parte de los sistemas dominantes de discursos e ideas que a veces surgen desde abajo. Al final de los setenta y ochenta hubo un caso muy claro en el que se observó esta dinámica, que fue el concepto de atención primaria en salud. Fue un concepto que salió desde movimientos por la democratización y la descentralización de la salud del sistema hospitalario de alta tecnología, para que sirviera a todo el mundo y no solamente a las poblaciones más privilegiadas. Poco a poco fue apropiado y desvirtuado. Podemos decir que el desarrollo sustentable también surgió de ciertos cuestionamientos desde el movimiento ambientalista, y que

7 Ver pactoecosocialdelsur.com 
las propuestas feministas sobre cómo el desarrollo también era un instrumento para la reproducción patriarcal, fue apropiada y subvertida a través de programas para incorporar la mujer al mal llamado desarrollo.

Esto siempre ocurre y tenemos que estar muy vigilantes y no caer en la trampa. Ha pasado con el buen vivir, especialmente en los gobiernos progresistas de Evo Morales y Rafael Correa, que en Ecuador y Bolivia usaron muy bien la retórica del buen vivir para sus propios beneficios, al mismo tiempo que reprimían por debajo las organizaciones ambientalistas, ecologistas y feministas y de los indígenas para perpetuar su modelo extractivista . Eso lo podemos vincular con la pregunta de cómo fomentamos nuevos órdenes sociales, económicos, políticos, culturales que no reproduzcan los vicios y la brutalidadde los existentes. En ese sentido considero que hay dos cosas importantes: una no pensar que hay una sola forma de hacer las cosas, porque la izquierda que ha llegado al poder - termina convirtiéndose en una nueva forma de orden, en un nuevo pensamiento único. Esto está pasando en México con Andrés Manuel López Obrador que en este momento está reprimiendo y tratando de darle vía a la exterminación de los zapatistas, de imponer el famoso tren Maya para abrir los megaproyectos del desarrollo para Chiapas. Es horrible entonces que a nombre del socialismo se implante de nuevo el modelo único con el mismo tipo de excesos que se critican. Entonces, las barbaries van a seguir ocurriendo, pero por lo menos estamos cada vez más conscientes del vínculo que existe en ellas y las formas de existir patriarcal, racista y capitalista que desde hace varios de miles de años existen. Tenemos que comenzar a seguir en serio ese largo camino de las transiciones a formas de existir y de realizar la sociedades no patriarcales, no racistas y no capitalistas.

Y una última cosa, ese proyecto no lo van a realizar ni los ricos ni los poderosos ni los Estados. Perdamos la ilusión de que los Estados lo van a hacer. No lo van a realizar, aunque podrían jugar un papel importante en algún momento y podemos luchar por democratizar el Estado hasta cierto punto, sistémicamente, ontológicamente, socialmente, para, como lo hacen muchos movimientos, presionar al Estado para que cumpla con sus labores de defender los derechos sociales, culturales, económicos y humanos de las poblaciones. Pero no pensemos que se va hacer desde el Estado; se va hacer especialmente desde abajo, desde los colectivos, tal vez con colaboración de funcionarios del Estado a nivel regional y local pero ese proyecto de transiciones que estamos pensando es más amplio.

MCH: Arturo muchas gracias por tus provocaciones divergentes desde el pluriverso, siempre bienvenidas.

AE: Muchísimas gracias por los comentarios tan interesantes que de nuevo extiendo a Ciespal. 


\section{Referencias y recomendaciones bibliográficas}

Chaparro, M (2015): Claves para repensar los medios y el mundo que habitamos. La distopía del desarrollo. Desde Abajo.

Escobar, A. (2019): Autonomía y diseño. La realización de lo comunal. Editorial Universidad del Cauca.

Escobar, A. (2007). La Invención del Tercer Mundo. Editorial el Perro y la Rana.

Foucault, M. (1963). Topologías (Dos conferencias radiofónicas). Versión escrita de Defert, D. (1984) En: http://hipermedula.org/wp-content/uploads/2013/og/michel foucault heterotopias y cuerpo utopico.pdf

Kothari, A., Salleh, A., Escobar, A., Demaría, F. \& Acosta, A. (2009). Pluriverso. Un diccionario del posdesarrollo. Icaria- Antrazy.

Naciones Unidas. Comisión Mundial para el ambiente y Desarrollo. (1987). Informe Nuestro Futuro Común. Coordinado por: Broundtland, G. H.

W. Sachs. (editor) (1992). Diccionario del desarrollo. Una guía del conocimiento como poder. PRATEC: Perú. (primera edición en inglés en 1992). En: https://www.uv.mx/mie/ files/2012/10/SESION-6-Sachs-Diccionario-Del-Desarrollo.pdf 